It is striking that in Mr. Stallard's case the acuity was 6/24 and in mine $6 / 9$ partly. The explanation must be that the refractive index of the cornea is so near to that of the aqueous that irregularities of the posterior surface have not a great effect upon the refraction. A very small irregularity of the anterior surface causes great distortion because the difference between the indices of the air and the cornea is great. In spite of this explanation it is surprising that a large bowl-shaped depression which was not even centrally placed should allow an acuity of over 6/12.

It is difficult to be quite certain that any change took place in the cornea during the year that it was under observation, but a year ago I did not notice the flattening of the anterior surface. The case was shown to the Midland Ophthalmological Society and my colleague, Mr. Rudd, thought that it was present. To-day it is obvious, and so it is probable that a change has taken place. The alteration in the angle of the cylinder and the improved acuity is further evidence of change. The presence of an area of sclerosis in this part of the cornea suggests that the anomaly is due to contraction, and this must probably be ascribed to some inflammatory process induced by the lead burn. Judging by my drawing made a year ago, and the present appearance, I think that the bowl is now less steep and that the edges shelve off more into the surrounding cornea than they did at that time.

\title{
SPONTANEOUS CURE OF CATARACT
}

BY

\section{T. HARRISON BUtLER}

BIRMINGHAM

IT is well known that changes may take place in a nuclear cataract which end in restoration of sight, but it cannot be often that all the stages of this transformation have been observed.

I have already recorded one example of this process in "An Illustrated Guide to the Slit-lamp," p. 85. Here the nucleus of a cataract had diminished in size, and the whole of the cortex had become fluid, with the result that the nucleus dropped below the line of sight, and the patient obtained with a suitable spherical correction an acuity of $6 / 18$.

The following is another example :-

Mr. A. B. consulted me in my rooms on March 24, 1914.

The right lens had been extracted by Mr. Fulford Eales in June, 1913. The vision of this eye, with suitable correction, was $6 / 5$ partly. The media were clear, and the fundus normal in all respects. The left eye contained a mature cataract. I made no note of anything unusual in its aspect. 
On May 17, 1927, thirteen years after the first visit, Mr. A. B. consulted me again. He complained, "that the sight of the left eye was returning, and that in consequence he was greatly worried by diplopia, and had difficulty in appreciating the distance of objects." His uncorrected vision with this eye was now 2/60.

I found marked iridodonesis. The lens nucleus had dropped, exposing about one-third of the pupil, and through the clear segment I obtained a perfect view of a normal fundus.

The appearance seen by ordinary focal illumination is shown in Fig. 1. There is a shrunken opaque nucleus floating within the capsule. Fig. 2 shows the lens in optical section, viewed with the narrow beam of the slit-lamp. There is centrally a hard shrunken

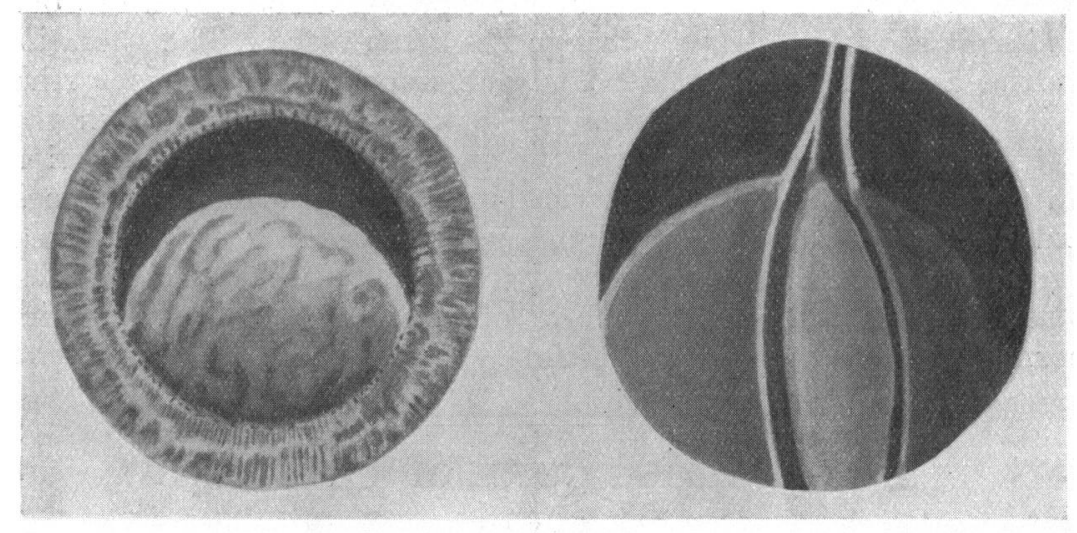

FIG. 1 .

FIG. 2.

nucleus floating in the capsule. In addition to the anterior and posterior capsule, there is attached to the anterior capsule, above, a third membrane which is figured in the drawing. This may be either a fold in the capsule, or, as I think more probable, a remnant of the condensed lens tissue that covers the adult nucleus, a sort of "internal capsule." In many senile lenses the line of demarcation between cortex and adult nucleus is so definite that it gives the impression that the central part of the lens is enclosed in an internal capsule. A drawing of a lens of this type will be found on p. 87 of the work mentioned above.

On April 12, 1930, I examined my patient again, and found that the nucleus had now sunk so far down, that only its upper edge could be seen. It was now clear of the normal pupil area. The acuity with $+10.5 \mathrm{D}$. sph., and $+0.5 \mathrm{D}$. cyl., axis horizontal was 6/9. The media were perfectly clear, and the fundus normal. The capsules were normal in texture, and showed no thickening or opacity.

Spontaneous cure of cataract may result from absorption of the 
whole contents of the capsules. The following is an example:Some ten years ago, Miss Ethel White, my House Surgeon at the Warneford Hospital, Leamington, performed a preliminary iridectomy upon an elderly man. The operation, performed under my immediate supervision, was technically perfect, and I feel certain that the capsule was not wounded. Careful examination with focal illumination and a lens failed to reveal any lesion of the anterior capsule. The operation was followed by considerable inflammatory reaction, which cleared up perfectly. After about a month I detected a notch in the north-west quadrant of the lens. At first it was only just visible and I regarded it a congenital notch in the lens. An anomaly of this nature is figured in my "Guide to the Slit-lamp" on p. 105. The defect gradually increased in size, till eventually after about six months the whole lens absorbed, and the patient reaped all the advantages of an extraction without the danger and trouble of this operation. The process began far away from the site of any possible puncture of the capsule and I am quite certain that it was not in any way caused by such an accident. It may have been due to the inflammation or to some change in the nutrition of the lens induced by the iridectomy.

My first case has some bearing upon the discussion that has recently taken place regarding the advisability of operating upon a single cataract. The fact that occasionally a Morgagnian cataract develops has been given as an excuse for extracting a cataract when the other eye has adequate vision. This condition is not the normal end of a senile cataract, it is a disease of cataract, and is rare in England. In Palestine we saw Morgagnian cataracts fairly frequently, but we never regarded the extraction as unusually difficult; in fact, my colleague, Mr. Edmund Cant, used to say that he preferred them to the ordinary extractions. I have seen several patients, some of them my own, who complain bitterly of the diplopia caused by the removal of a single cataract. One example is impressed upon my memory. A personal friend of mine was the fortunate possessor of two perfect eyes with an acuity of $6 / 3$ easily. Unfortunately his teeth were not equally perfect, and an apical abscess led to the development of a posterior cortical opacity in one lens, the so-called cataracta complicata. The whole lens became rapidly opaque. I strongly advised him to have nothing done, warning him that successful operation would be followed by diplopia. However, he had the cataract removed in Switzerland, and suffered from intolerable diplopia. I could only advise him to wear a ground glass in front of the aphakic eye. Quite recently I saw a lady who had had a single cataract removed. She not only complained of very troublesome diplopia but had developed postoperative glaucoma.

The patient A.B. described above began to complain of doublevision when the acuity of the left eye was only $2 / 60$. 